\title{
Evaluation and Promotion Strategy on Cultural Competitiveness of Cities Along the "Xi'an-Chengdu High-speed Railway"
}

\author{
Ying $\mathrm{Zuo}^{1}$ Yan $\mathrm{Cui}^{2}{ }^{2 *}$ \\ ${ }^{1}$ City and Environment College, Northwest University, Xi'an, Shaanxi 710127, China \\ ${ }^{2}$ Architecture and Civil Engineering Department, Xi'an University of Science and Technology, Xi'an, Shaanxi 710054, \\ China \\ *Corresponding author. Email: 87086559@qq.com
}

\begin{abstract}
This article selects cities along the Xi'an to Chengdu High-speed Railway as the research object, to research the urban cultural competitiveness. In the understanding of urban cultural competitiveness based on the connotation and evaluation index system both at home and abroad research, the researchers explore the construction of urban cultural competitiveness evaluation index system in the study area. Based on the relevant statistics 2012-2016 research area, using the factor analysis method to extract principal component, the researchers compute research area comprehensive urban cultural competitiveness rankings. Based on the results of the analysis, they put forward some strategies to enhance the competitiveness of city culture.
\end{abstract}

Keywords: Xi'an-Chengdu High-speed Railway, urban cultural competitiveness, the competitiveness, the evaluation index system

\section{INTRODUCTION}

As science, technology and economy pick up, so does China's investment in infrastructure. The construction of high-speed railway has improved the inter-provincial rail transit system and further promoted the coordinated development of cities along the line.

As the spiritual connotation and soul of a city, cultural energy serves as the foundation and key to its sustainable development. It is composed of multiple indicators and elements, which sway the core competitiveness and growth pole construction of cities. Therefore, governments at all levels regard improving the cultural competitiveness of cities as crucial development measure.

"Urban cultural competitiveness" refers to the ability of a city, compared with other cities, to compete against or even surpass actual and potential competitors in the flow of cultural resources in the context of economic globalization and regional integration, to obtain lasting competitive advantages and realize urban cultural values. [1] Thanks to its own characteristics, urban cultural competitiveness is defined by comprehensiveness, dynamism, regionalism and difference, and is affected by various social, economic,

*Fund: General project of Shaanxi Provincial Science and Technology Planning Project (Project No.: 2018JQ5141). values and natural elements. Therefore, it is difficult to propose quantitative description. There exists no universal standard system in the academic field. The connotation of urban cultural competitiveness is mainly defined from the aspects of urban cultural elements and studied from the perspective of cultural modernization. Most of the studies are qualitative and few are quantitative. Therefore, it is imperative to select a specific region and establish a multi-layer urban cultural competitiveness index system. [2]

In this paper, the connotation of urban cultural competitiveness is defined. The influence sphere of urban culture is wide, which can sway other cities in the competition. Therefore, in the construction of the index, this paper summarizes the previous studies of scholars, draws on their index system, builds the index system of urban cultural competitiveness according to the actual situation of the research area, and demonstrates with examples, so as to provide theory and basis for the promotion of urban cultural competitiveness.

The opening of Xi'an-Chengdu high-speed railway has greatly enhanced the role of cultural development in urban transformation and development. The cultures of cities along the high-speed railway will encounter unprecedented exchanges and competition. However, problems are inevitable, such as the destruction of cultural heritage, the loss of urban individuality, and the 
departure of cultural concepts from the development requirements of the era. Therefore, Xi'an, Hanzhong, Guangyuan, Deyang, Mianyang and Chengdu, six major cities along the "Xicheng High-speed Railway" are selected as the research objects (hereinafter referred to as the "research area") to conduct a study on their urban cultural competitiveness. The construction of cultural facilities, the general situation of cultural industry, the situation of cultural innovation, the quality of life service, and the sphere of influence of culture are analyzed and compared [3]. It is concluded that urban cultural competitiveness can better the image of cities along the railway and highlight their cultural characteristics, so as to accelerate the construction of urban culture and improve urban economy.

\section{RELATED RESEARCH, INDEX SELECTION AND RESEARCH METHODS}

\section{A. Related research}

The research on evaluation index system of urban cultural competitiveness is not a new thing in China and foreign countries. In 1998, Linnamaa established the urban competitiveness evaluation system, holding that the main determinants of urban competitiveness were infrastructure, quality of life, government systems and policies, human resources and network members. [4] In 2000, Douglas Webster pointed out that the four indicators of urban competitiveness are economic structure, regional endowment, human resources and institutional environment. In 2008, London Development Agency (LDA) published the report London: Cultural Audit, which analyzed the development status and cultural infrastructure of creative cultural industries in London, Paris and other world-famous cities, and compared their cultural functions, cultural activities, cultural needs, cultural output and cultural consumption [5].

The most awarded research on evaluation index of cultural competitiveness in China is that at the end of the 20th century, Dr. Ni Pengfei divided cultural competitiveness into four dimensions: values, innovation, communication and entrepreneurship. In 2009, based on Ni Pengfei's theory, Professor Lei Ming added indicators such as natural and historical cultural resources, family and economic system, and conducted empirical analysis. In 2006, in order to enhance urban innovation and sustainable development, Zhao Dexing started from the connotation of cultural competitiveness, took improving the overall quality of citizens as starting and homing point, created 7 secondary indicators including economy, resources and environment, and focused on the starting point, role, difficulties and construction principles of the evaluation index system of urban cultural competitiveness. In 2009, when studying cultural competitiveness, the
Chinese Academy of Sciences put forward the idea of taking cultural market competitiveness, cultural efficiency competitiveness and cultural resource competitiveness as secondary indicators from the perspective of modern culture, believing that the trio are positively correlated with urban cultural competitiveness. In 2014, Zhang Jinhua compared the cultural competitiveness of 14 cities, including Ji'nan, and established an index system of cultural facilities, cultural industry, cultural innovation, quality of life service and cultural radiation. In 2016, Cultural Development Institute of Communication University of China released Annual Report on China's Urban Competitiveness (2016). The report constructs five index systems of cultural endowment, cultural economy, cultural management, cultural potential and cultural exchange, and adds the analysis of "coefficient of variation" to the evaluation of urban cultural competitiveness.

\section{B. Construction of evaluation index system}

The evaluation index systems of urban cultural competitiveness are related and serve as an organic whole that can accurately reflect the cultural competitiveness of cities. According to the definition of urban cultural competitiveness, the authors consulted the research results and viewpoints of scholars, screened out the factors of urban cultural competition and the components of cultural competitiveness factors, drew on the previous models to redefine them, and then constructed the evaluation index system model. Through correlation analysis of relevant data, 23 indicators are selected to divide the evaluation system of urban cultural competitiveness into three layers, namely, the first layer of goal, the second layer of criterion and the third layer of evaluation index. The specific content is shown in "Table I". 
TABLE I. EVALUATION INDEX SYSTEM OF URBAN CULTURAL COMPETITIVENESS

\begin{tabular}{|c|c|c|}
\hline Goal layer & Criterion layer & Evaluation index layer \\
\hline \multirow{5}{*}{$\begin{array}{l}\text { Urban } \\
\text { cultural } \\
\text { competitive } \\
\text { ness }(\mathrm{R})\end{array}$} & Cultural facilities $\left(\mathrm{R}_{1}\right)$ & $\begin{array}{l}\left(\mathrm{R}_{11}\right) \text { Cultural center } \\
\left(\mathrm{R}_{12}\right) \text { Number of public libraries } \\
\left(\mathrm{R}_{13}\right) \text { Number of museums } \\
\left(\mathrm{R}_{14}\right) \text { Number of stadiums } \\
\left(\mathrm{R}_{15}\right) \text { Number of theaters }\end{array}$ \\
\hline & $\begin{array}{l}\text { Cultural industry overview } \\
\qquad\left(\mathrm{R}_{2}\right)\end{array}$ & $\begin{array}{l}\left(\mathrm{R}_{21}\right) \text { Proportion of tourism revenue in GDP }(\%) \\
\left(\mathrm{R}_{22}\right) \text { Number of enterprises in the film and television culture industry } \\
\left(\mathrm{R}_{23}\right) \text { Practitioners in sports and entertainment Industry } \\
\left(\mathrm{R}_{24}\right) \text { Number of national key cultural relics protection units }\end{array}$ \\
\hline & $\begin{array}{l}\text { Cultural innovation } \\
\text { construction }\left(\mathrm{R}_{3}\right)\end{array}$ & $\begin{array}{l}\left(\mathrm{R}_{31}\right) \text { Number of colleges and universities } \\
\left(\mathrm{R}_{32}\right) \text { Number of patent grants } \\
\left(\mathrm{R}_{33}\right) \text { Proportion of expenditure on education in local fiscal budgets }(\%) \\
\left(\mathrm{R}_{34}\right) \text { Proportion of science and technology expenditure in local fiscal budget }(\%)\end{array}$ \\
\hline & $\begin{array}{l}\text { Quality of life services } \\
\qquad\left(\mathrm{R}_{4}\right)\end{array}$ & $\begin{array}{l}\left(\mathrm{R}_{41}\right) \text { Per capita disposable income of urban residents (ten thousand yuan) } \\
\left(\mathrm{R}_{42}\right) \text { Number of people participating in basic endowment insurance (ten thousand people) } \\
\left(\mathrm{R}_{43}\right) \text { Greenery coverage of urban area }(\%) \\
\left(\mathrm{R}_{44}\right) \text { Urban registered unemployment rate }(\%) \\
\left(\mathrm{R}_{45}\right) \text { Park green area per capita (square meters) }\end{array}$ \\
\hline & $\begin{array}{l}\text { Cultural sphere of } \\
\text { influence } \\
\quad\left(\mathrm{R}_{5}\right)\end{array}$ & $\begin{array}{l}\left(\mathrm{R}_{51}\right) \text { Number of mobile phone users (ten thousand) } \\
\left(\mathrm{R}_{52}\right) \text { Number of internet users (ten thousand) } \\
\left(\mathrm{R}_{53}\right) \text { Number of overseas tourists received per year }(10,000 \text { people }) \\
\left(\mathrm{R}_{54}\right) \text { Number of well-known trademarks } \\
\left(\mathrm{R}_{55}\right) \text { TV broadcast coverage }(\%)\end{array}$ \\
\hline
\end{tabular}

The foundation of a city's cultural competitiveness is cultural infrastructure, which can be reflected through cultural centers and public libraries, while museums reveal its cultural deposits, and stadiums and theaters the rich cultural life of residents. The more complete the cultural facilities, the more they are in quantity and coverage, the better the city's public cultural services and the richer residents' cultural life.

Since cultural industry can directly reveal the scale and development of a city's cultural industry, it is selected to show the city's cultural competitiveness. [7] The proportion of tourism income can be adopted to showcase the development of urban cultural industry. Number of enterprises in the film and television culture industry $\left(\mathrm{R}_{22}\right)$ and their employees can reflect the scale of urban cultural industry. Number of national key cultural relics protection units $\left(\mathrm{R}_{24}\right)$ conveys the historical and cultural deposits of a city, sways the tourism development of a city, and indirectly determines the level of urban cultural development.

Cultural innovation cannot be separated from government's support in terms of policies and funds. The proportion of expenditure on education in local fiscal budgets $\left(\mathrm{R}_{33}\right)$ and of science and technology in local fiscal budgets $\left(R_{34}\right)$ are selected to show the city's emphasis on and support for cultural innovation. Number of colleges and universities $\left(\mathrm{R}_{31}\right)$ can reflect the city's investment in cultural innovation talents. The number of patent grants $\left(\mathrm{R}_{32}\right)$ can reflect the level of cultural innovation in the city.

Quality of residents' life service reflects the richness of their cultural activities and indirectly reflects the city's cultural competitiveness. The material living standard of residents is determined by their income, which can be shown through per capita disposable income of urban residents $\left(\mathrm{R}_{41}\right)$. The social security coverage rate can be reflected by number of people participating in basic endowment insurance $\left(R_{42}\right)$, the greenery coverage of urban area $\left(R_{43}\right)$ and park green area per capita $\left(R_{45}\right)$ reflect the environment of urban residence, and urban registered unemployment rate $\left(\mathrm{R}_{44}\right)$ reflects the employment of the city.

Cultural sphere of influence is one of the manifestations of the influence of urban cultural competition. Number of mobile phone users $\left(R_{51}\right)$, Internet users $\left(\mathrm{R}_{52}\right)$ and $\mathrm{TV}$ broadcast coverage $\left(\mathrm{R}_{55}\right)$ reflect the diversity and effectiveness of urban cultural media. Number of well-known trademarks $\left(R_{54}\right)$ and number of overseas tourists received per year $\left(R_{53}\right)$ reflect the sway and attraction of cultural competition to the outside world.

\section{Data source}

Data adopted in this study are from statistical yearbook of various cities from 2012 to 2016, covering Xi'an Statistical Yearbook (2012-2016), Chengdu Statistical Yearbook (2012-2016), Hanzhong Statistical Yearbook (2012-2016), Mianyang Statistical Yearbook (2012-2016), Deyang Statistical Yearbook (2012-2016), and Guangyuan Statistical Yearbook (2012-2016). Some missing data are calculated based on the data of the year before and after. 


\section{ANALYSIS AND CALCULATION OF MODEL CONSTRUCTION}

\section{A. Reliability}

The data must be reliable and effective. Before relevant calculation, its reliability should be tested and the reliability of the data should be consistently tested. Cronbach's $\alpha$ reliability was often detected by SPSS. The higher the value, the more reliable it is. In general, values between 0.60 and 0.65 are considered unreliable, values between 0.65 and 0.70 are the minimum acceptable, values between 0.70 and 0.80 are fairly good, and values between 0.80 and 0.90 are excellent. [8] SPSS20.0 software was adopted to carry out factor analysis on relevant data, and internal consistency detection was made on the data concerning urban cultural competitiveness. The result is 0.869 , which is excellent and can be used for subsequent analysis and calculation. [9]

\section{B. Model analysis}

The data collected in the research area from 2012 to 2016 were standardized and calculated to obtain the comprehensive ranking of urban cultural competitiveness, and the main factors affecting urban cultural competitiveness were analyzed. Correlation test is essential before factor analysis. Therefore, before using SPSS20.0 statistical analysis software for factor analysis, the authors firstly conducted correlation test on the data. KMO test and Bartlett's test of sphericity confirmed the correlation of the results. The common factor can be extracted from it, the factor loading matrix after orthogonal rotation of each indicator or variable can be calculated, and the variance table and principal component factor score coefficient matrix of each interpretation of factors can be obtained. Then, the weights of the three-layer and second-layer indexes are calculated, and the cultural competitiveness of each city is calculated based on the basic data.

\section{Model calculation}

SPSS20.0 software was used to calculate the basic data of Xi'an in 2012. First, data dimension reduction was carried out on the five indicators included in cultural facilities $\left(\mathrm{R}_{1}\right)$, and fixed factor and main component are selected, calculating the factor loading matrix after orthogonal rotation of each indicator or variable and the corresponding eigenvalue, contribution rate and cumulative contribution rate of each factor (See "Table II"), and component score coefficient matrix (See "Table III"). When the component factor value is taken, the cumulative variance of the initial eigenvalue should not be less than $85 \%$, so that the data is considered meaningful. The authors calculated the weight coefficient of the three-layer of cultural centers $\left(\mathrm{R}_{11}\right)$, number of public libraries $\left(\mathrm{R}_{12}\right)$, number of museums $\left(R_{13}\right)$, number of stadiums $\left(R_{14}\right)$ and theaters $\left(\mathrm{R}_{15}\right)$, and then obtained the intermediate value of Xi'an cultural facilities $\left(R_{1}\right)$ in 2012 . The intermediate value and weight of the second-layer can be obtained by the same method. Finally, according to the basic data of Xi'an in 2012, the city's cultural competitiveness is obtained. The specific calculation formula is as follows.

$\mathrm{R}$ score of urban cultural competitiveness of Xi'an in 2012

$$
\begin{aligned}
& \mathrm{Z}_{11 \mathrm{Xi}{ }^{\prime} \text { n }}=\mathrm{F} 1 * \mathrm{M} 1+\mathrm{F} 2 * \mathrm{M} 2 \\
& \mathrm{Z}_{1 \mathrm{Xi} \text { 'an }}=\mathrm{Z}_{11}+\mathrm{Z}_{12}+\mathrm{Z}_{13}+\mathrm{Z}_{14}+\mathrm{Z}_{15} \\
& \mathrm{Z}_{\mathrm{Xi} \text { 'an }}=\mathrm{Z}_{1}+\mathrm{Z}_{2}+\mathrm{Z}_{3}+\mathrm{Z}_{4}+\mathrm{Z}_{5} \\
& \mathrm{~W}_{11 \mathrm{Xi}^{\prime} \mathrm{an}}=\mathrm{Z}_{11} / \mathrm{Z}_{1} \\
& \mathrm{~W}_{1 \mathrm{Xi}{ }^{\prime} \mathrm{an}}=\mathrm{Z}_{1} / \mathrm{Z} \\
& \mathrm{R}_{1 \text { Xi'an }}=\mathrm{W}_{11} * \mathrm{R}_{11}+\mathrm{W}_{12} * \mathrm{R}_{12}+\mathrm{W}_{13} * \mathrm{R}_{13}+\mathrm{W}_{14} * \mathrm{R}_{14}+\mathrm{W}_{15} * \\
& \mathrm{R}_{15} \\
& \mathrm{R}_{X^{\prime}{ }^{\prime} \mathrm{n}}=\mathrm{R}_{1}+\mathrm{R}_{2}+\mathrm{R}_{3}+\mathrm{R}_{4}+\mathrm{R}_{5}
\end{aligned}
$$

Among them, $\mathrm{F} 1$ is the component 1 value of $\mathrm{R}_{11}$, $\mathrm{F} 2$ is the component 2 value of $\mathrm{R}_{11} ; \mathrm{M} 1$ is the component 1 coefficient of $\mathrm{R}_{11}, \mathrm{M} 2$ is the component 2 coefficient of $R_{11} ; Z_{11}, Z_{1}, Z$ are intermediate values of $\mathrm{R}_{11}, \mathrm{R}_{1}, \mathrm{R}_{1}, \mathrm{~W}_{11}$ is the weight of $\mathrm{R}_{11}$, and $\mathrm{W}_{1}$ is the weight of $R_{1}$.

TABLE II. THE TOTAL VARIANCE OF INTERPRETATION OF FACTORS

\begin{tabular}{|c|c|c|c|c|c|c|c|c|c|}
\hline \multirow{2}{*}{ Component } & \multicolumn{3}{|c|}{ Initial eigenvalue } & \multicolumn{2}{c|}{ Sum of squares extracted } & \multicolumn{3}{c|}{ Sum of squares of rotation } \\
\cline { 2 - 10 } & Total & Variance $\%$ & Cumulation $\%$ & Total & $\begin{array}{c}\text { Variance } \\
\%\end{array}$ & $\begin{array}{c}\text { Cumulation } \\
\%\end{array}$ & $\begin{array}{c}\text { Total } \\
\%\end{array}$ & $\begin{array}{c}\text { Variance } \\
\%\end{array}$ & $\begin{array}{c}\text { Cumulation } \\
\%\end{array}$ \\
\hline 1 & 3.732 & 74.646 & 74.646 & 3.732 & 74.646 & 74.646 & 3.492 & 69.844 & 69.844 \\
\hline 2 & 0.940 & 18.802 & 93.448 & 0.940 & 18.802 & 93.448 & 1.180 & 23.604 & 93.448 \\
\hline 3 & 0.233 & 4.667 & 98.115 & & & & & & \\
\hline 4 & 0.094 & 1.885 & 100.000 & & & & & & \\
\hline 5 & $1.264 \mathrm{E}-006$ & $2.528 \mathrm{E}-005$ & 100.000 & & & & & & \\
\hline
\end{tabular}


TABLE III. COMPONENT FACTOR SCORE COEFFICIENT MATRIX

\begin{tabular}{|l|l|l|}
\hline \multirow{2}{*}{} & \multicolumn{2}{|c|}{ Component } \\
\cline { 2 - 3 } & 1 & 2 \\
\hline $\mathrm{R}_{11}$ & 0.251 & 0.069 \\
\hline $\mathrm{R}_{12}$ & 0.286 & -0.079 \\
\hline $\mathrm{R}_{13}$ & 0.238 & 0.127 \\
\hline $\mathrm{R}_{14}$ & 0.324 & -0.256 \\
\hline $\mathrm{R}_{15}$ & -0.174 & 0.950 \\
\hline
\end{tabular}

Similarly, it can be seen that the final results of cultural competitiveness of each city in the research area from 2012 to 2016 are shown in "Table IV".

TABLE IV. SCORE AND RANKING OF URBAN CULTURAL COMPETITIVENESS IN THE RESEARCH AREA

\begin{tabular}{|c|c|c|c|c|c|c|c|c|}
\hline Year & City & $\mathbf{R}_{1}$ & $\mathbf{R}_{\mathbf{2}}$ & $\mathbf{R}_{\mathbf{3}}$ & $\mathbf{R}_{\mathbf{4}}$ & $\mathbf{R}_{\mathbf{5}}$ & $\mathbf{F}$ & Ranking \\
\hline \multirow{6}{*}{2012} & Xi'an & 36.50 & 1567.86 & 3573.11 & 105.09 & 467.40 & 790.16 & 2 \\
\hline & Hanzhong & 13.54 & 68.34 & 157.61 & 51.63 & 77.50 & 63.63 & 4 \\
\hline & Chengdu & 44.41 & 1172.87 & 7755.74 & 111.68 & 571.33 & 1230.54 & 1 \\
\hline & Mianyang & 12.63 & 836.34 & 413.08 & 49.69 & 121.66 & 211.91 & 3 \\
\hline & Deyang & 8.47 & 87.88 & 60.86 & 30.70 & 100.22 & 59.63 & 5 \\
\hline & Guangyuan & 9.26 & 61.54 & 33.58 & 37.17 & 68.21 & 42.97 & 6 \\
\hline \multirow{6}{*}{2013} & Xi'an & 38.36 & 7205.83 & 1850.66 & 101.36 & 467.57 & 1944.78 & 1 \\
\hline & Hanzhong & 11.98 & 239.75 & 114.64 & 45.32 & 88.26 & 99.46 & 4 \\
\hline & Chengdu & 37.51 & 4807.65 & 4081.66 & 99.73 & 575.28 & 1846.83 & 2 \\
\hline & Mianyang & 12.62 & 3262.86 & 356.69 & 52.09 & 134.78 & 783.69 & 3 \\
\hline & Deyang & 9.36 & 326.18 & 42.69 & 36.14 & 102.68 & 105.28 & 5 \\
\hline & Guangyuan & 14.47 & 256.13 & 22.77 & 32.52 & 79.24 & 82.92 & 6 \\
\hline \multirow{6}{*}{2014} & Xi'an & 40.25 & 5966.69 & 4992.06 & 123.67 & 400.82 & 1949.11 & 2 \\
\hline & Hanzhong & 12.01 & 220.31 & 239.93 & 53.55 & 78.26 & 110.03 & 4 \\
\hline & Chengdu & 36.55 & 4049.83 & 8195.02 & 126.60 & 481.15 & 2358.40 & 1 \\
\hline & Mianyang & 13.37 & 3496.42 & 794.13 & 60.14 & 105.34 & 674.42 & 3 \\
\hline & Deyang & 9.57 & 321.21 & 106.19 & 51.60 & 94.20 & 99.26 & 5 \\
\hline & Guangyuan & 14.39 & 225.67 & 55.84 & 36.90 & 68.36 & 68.34 & 6 \\
\hline \multirow{6}{*}{2015} & Xi'an & 41.69 & 5503.56 & 9184.29 & 92.91 & 435.66 & 2755.84 & 2 \\
\hline & Hanzhong & 11.90 & 242.96 & 341.88 & 40.40 & 80.68 & 133.63 & 5 \\
\hline & Chengdu & 38.32 & 5467.72 & 12890.07 & 94.09 & 501.21 & 3382.07 & 1 \\
\hline & Mianyang & 13.36 & 3449.40 & 1512.96 & 42.91 & 114.73 & 979.28 & 3 \\
\hline & Deyang & 9.48 & 381.36 & 476.73 & 46.31 & 104.94 & 189.57 & 4 \\
\hline & Guangyuan & 14.30 & 239.70 & 99.28 & 26.51 & 70.54 & 87.45 & 6 \\
\hline \multirow{6}{*}{2016} & Xi'an & 42.85 & 5503.84 & 13217.79 & 102.00 & 463.32 & 3992.18 & 1 \\
\hline & Hanzhong & 11.90 & 248.81 & 389.12 & 40.31 & 113.01 & 159.87 & 5 \\
\hline & Chengdu & 44.52 & 6359.97 & 10618.76 & 98.50 & 577.84 & 3518.55 & 2 \\
\hline & Mianyang & 14.39 & 3163.71 & 1513.51 & 43.14 & 139.44 & 830.08 & 3 \\
\hline & Deyang & 9.48 & 393.93 & 477.39 & 48.13 & 175.15 & 214.11 & 4 \\
\hline & Guangyuan & 14.47 & 274.59 & 122.84 & 26.64 & 71.46 & 89.69 & 6 \\
\hline
\end{tabular}

\section{ANALYSIS OF MODEL RESULTS}

It can be seen from "Table IV" and "Fig. 1" that the ranking of cultural competitiveness of cities in the area in 2012 is Chengdu, Xi'an, Mianyang, Hanzhong, Deyang and Guangyuan. In 2013, the ranking was Xi'an, Chengdu, Mianyang, Hanzhong, Deyang and Guangyuan. In 2014, the ranking sequence was Chengdu, Xi'an, Mianyang, Hanzhong, Guangyuan and Deyang. Chengdu, Xi'an, Mianyang, Deyang, Hanzhong and Guangyuan in 2015 and Xi'an, Chengdu, Mianyang, Deyang, Hanzhong and Guangyuan in 2016. 


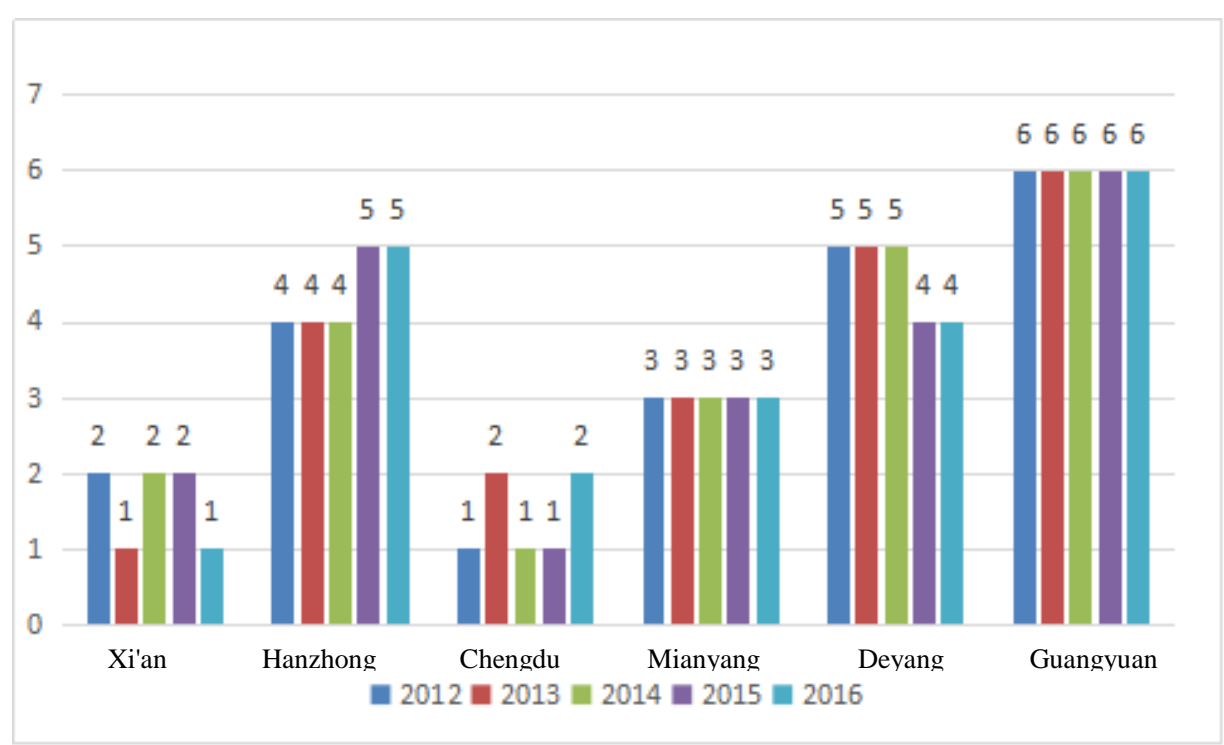

Fig. 1. The cultural competitiveness ranking of 6 cities in the research area from 2012 to 2016 .

The overall ranking of cultural competitiveness of cities in the research area has not changed much. In 2012, Chengdu took the first place, followed by Xi'an. In 2013, Xi'an overtook Chengdu and ranked first. In 2014 and 2015, Chengdu regained the first place. In 2016, Xi'an rose to the first place and Chengdu came second. As provincial capitals, Xi'an and Chengdu have stronger cultural competitiveness than other cities.

Xi'an is an important central city in western China and a base for scientific research, education and industry. As capital of thirteen dynasties, Xi'an is world-famous historical city and one of the top ten ancient capitals with profound cultural deposits.

Chengdu is an important central city in western region and a hub of science, technology, commerce, finance and transportation and communication in the southwest region. It is also one of the first national historical and cultural cities and the best tourist destination in China. [10] [11] These directly affect the cultural competitiveness of Xi'an and Chengdu.

Mianyang's ranking remained unchanged from 2012 to 2016, staying firmly in third place. From 2012 to 2014, Hanzhong ranked fourth, while Deyang fifth. In 2015 and 2016, the latter rose to become fourth. From 2012 to 2016, Guangyuan's urban cultural competitiveness has been at the bottom. The indicators are compared in detail below.

It can be seen from "Fig. 2" that in terms of cultural facilities(R1), Chengdu ranked first and Xi'an ranked second in 2012, which is largely due to the emphasis on and financial support of Xi'an to the construction of cultural facilities. As a result, the cultural facilities of Xi'an has been rising year by year, ranking first from 2013 to 2015. The decline of Chengdu indicates that
Chengdu has shifted its focus from hardware construction such as cultural facilities to soft services such as cultural innovation and tourism development. Hanzhong, Mianyang and Guangyuan have little difference in cultural facilities, while Deyang is the least optimistic. The changes in the four cities as a whole were small. The iconic cultural and entertainment facilities in a city include cultural centers, libraries, theaters and museums. As a non-profit public cultural service system, these four not only reflect the characteristics and image of a city, but also guarantee residents' cultural rights and accelerate urbanization. In order to improve the city's cultural competitiveness, each city should strengthen its financial support and develop a unique cultural service system different from other cities according to its own situation. 


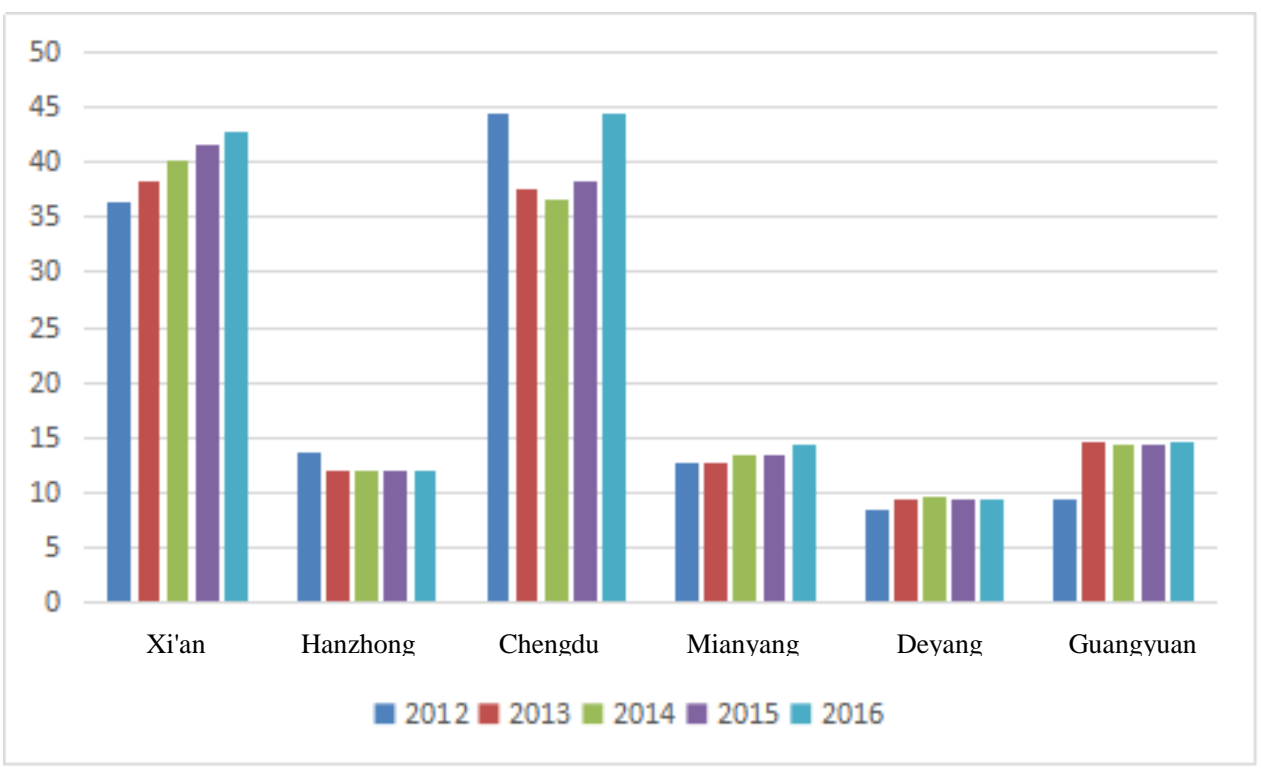

Fig. 2. Comparison of $R_{1}$ in 6 cities in the research area from 2012 to 2016.

"Fig. 3" shows that the cultural industry (R2) in each city has changed greatly from 2012 to 2016 . In 2013, the scores of cultural industries in all cities rose as a whole, among which those in $\mathrm{Xi}$ 'an, Chengdu and Mianyang rose significantly, indicating that the whole society pays more attention to this aspect. From 2012 to 2015, Xi'an ranked first, Chengdu second, Mianyang third, then Hanzhong and Guangyuan. In 2016, Chengdu ranked first, Xi'an second, Hanzhong and Guangyuan ranked last. Nowadays, government departments increasingly value cultural tourism in enhancing city's cultural competitiveness. Xi'an boasts numerous key cultural relics under protection and rich tourism resources. Sichuan also enjoys bountiful cultural tourism resources. With the promotion of regional tourism and the opening of "Xi'an-Chengdu high-speed railway", cities along the line should introduce more preferential policies and invest more money to develop unique cultural tourism products, so as to improve tourists' experience and satisfaction.

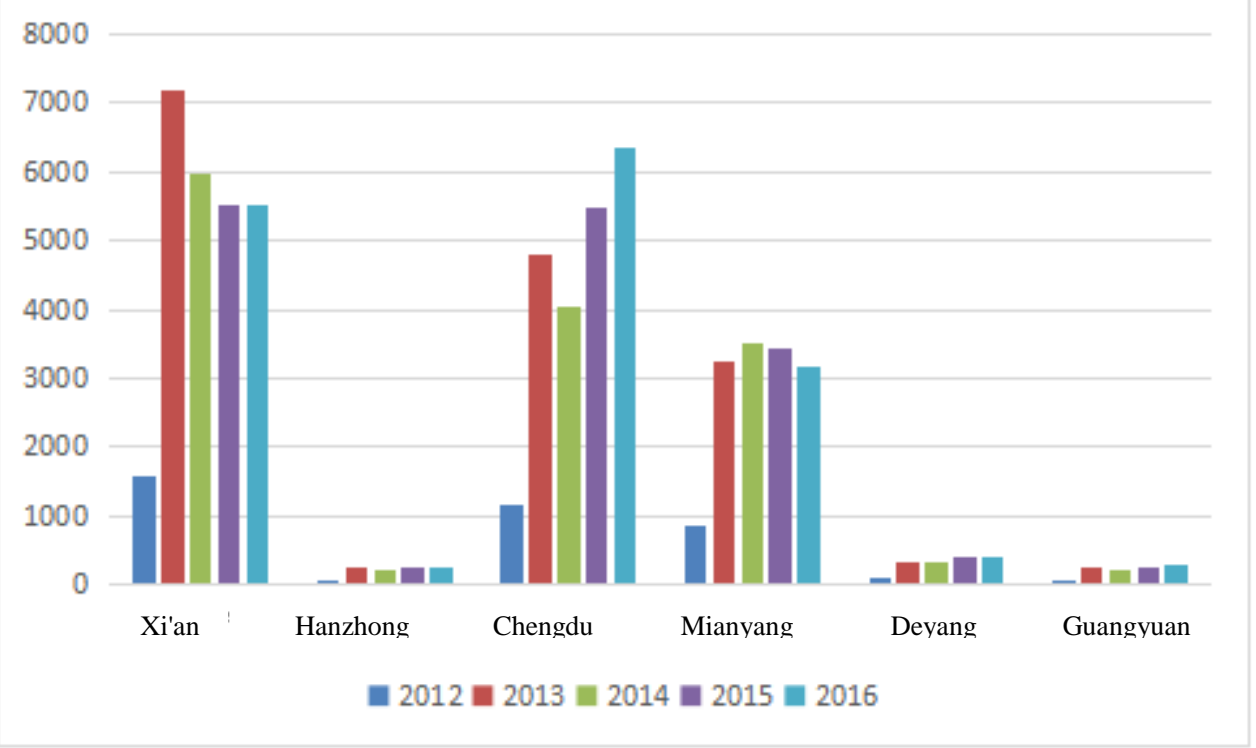

Fig. 3. Comparison of $R_{2}$ in 6 cities in the research area from 2012 to 2016.

"Fig. 4" shows that attraction of cultural innovation $\left(R_{3}\right)$ in all cities from 2012 to 2016 has increased, among which Xi'an enjoys the highest increase, while in 2013, it has decreased slightly. From 2012 to 2015,
Chengdu ranked first, Xi'an ranked second and Guangyuan ranked last. In 2016, Xi'an came first, Chengdu came second, and Guangyuan came last. This indicates that the government departments of the 
research area have made great efforts in cultural innovation. Xi'an enjoys many universities and national top scientific research institutions, so its cultural research strength should be strong. However, the reality is that most of them fail to become actual cultural innovation capabilities, which should be paid attention to by the government. The improvement of cultural innovation capacity involves the development of strategic emerging industries, service and low-carbon industries in a city, and relevant government departments should give more support to this aspect.

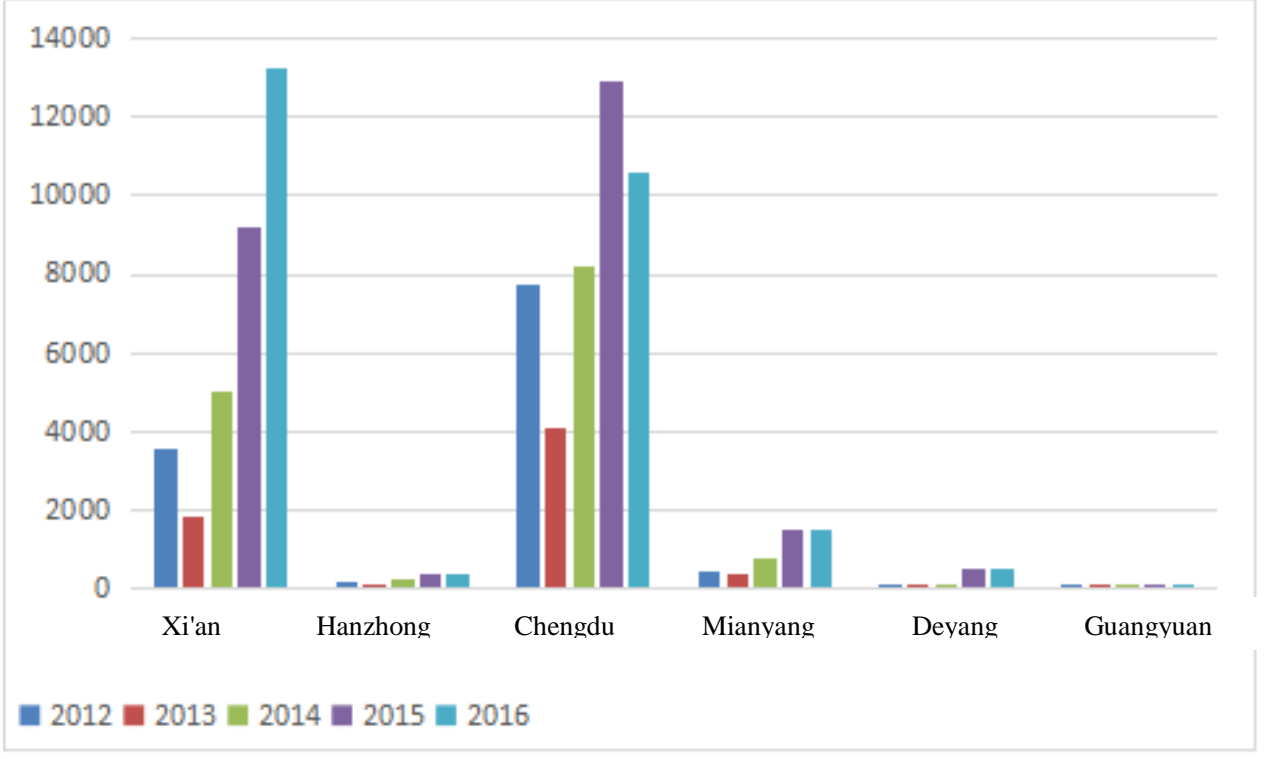

Fig. 4. Comparison of $R_{3}$ in 6 cities in the research area from 2012 to 2016.

"Fig. 5" shows that quality of life services $\left(\mathrm{R}_{4}\right)$ in the six cities in the research area has obviously changed from 2012 to 2016. Xi'an and Chengdu have a small gap in scores each year, ranking the top, while Hanzhong, Mianyang and Deyang have a small gap, with Guangyuan ranking the bottom. Material life is the basic guarantee for people's life. With the improvement of living standard, people pay more attention to material enjoyment and their disposable income influences their consumption. Government departments should attach importance to the construction of public welfare culture, enhance the construction of infrastructure, value environmental quality, and do a good job in ensuring the livelihood of residents.

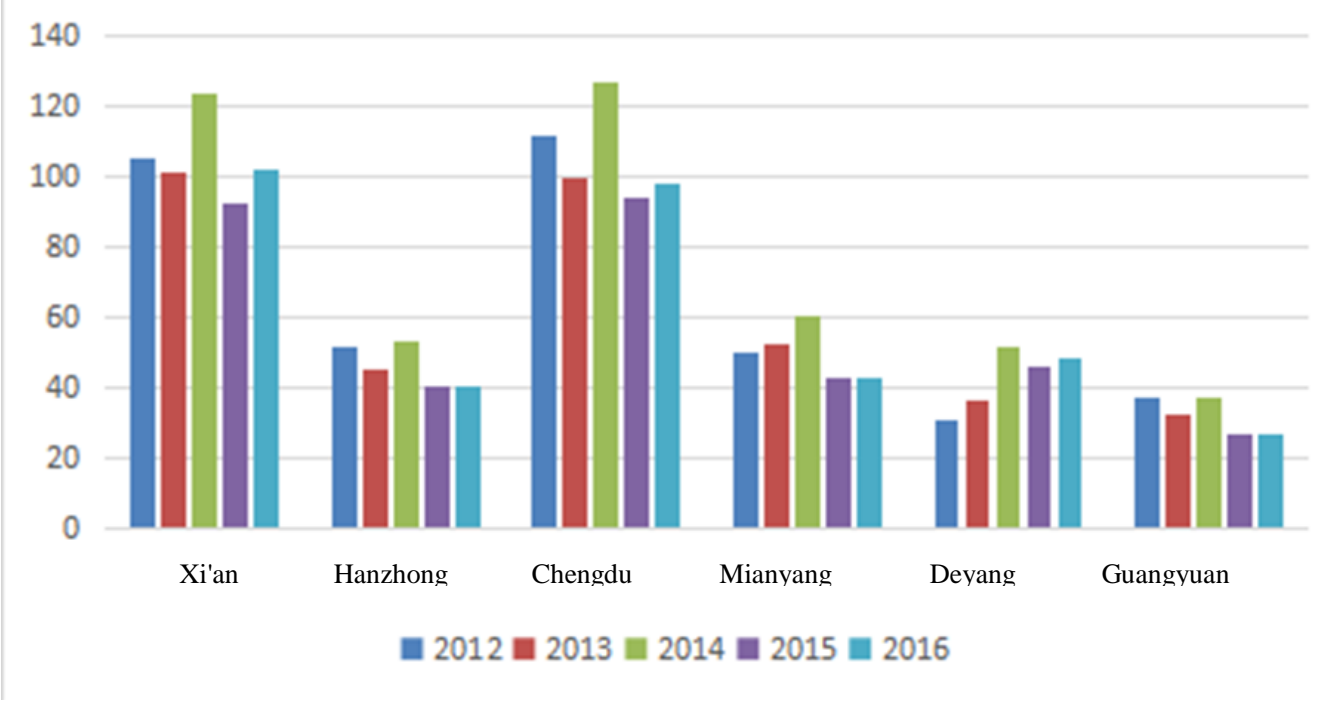

Fig. 5. Comparison of $R_{4}$ in 6 cities in the research area from 2012 to 2016. 
"Fig. 6" reveals a small change in the scores of the six cities in the study area from 2012 to 2016 as for cultural sphere of influence $\left(\mathrm{R}_{5}\right)$, with Chengdu ranking first, Xi'an second, Mianyang third and Guangyuan last. Urban cultural sphere of influence refers to the city's influence on the fields other than culture, industry and economy, which directly reflects the urban cultural competitiveness [12]. Chengdu and Xi'an boast long history, numerous unique tourist attractions, broad cultural sphere of influence and obvious advantages in urban competition. Other cities should also strengthen the construction of cultural resources, cultural facilities, expand the city's cultural sphere of influence, so as to enhance the city's competitiveness.

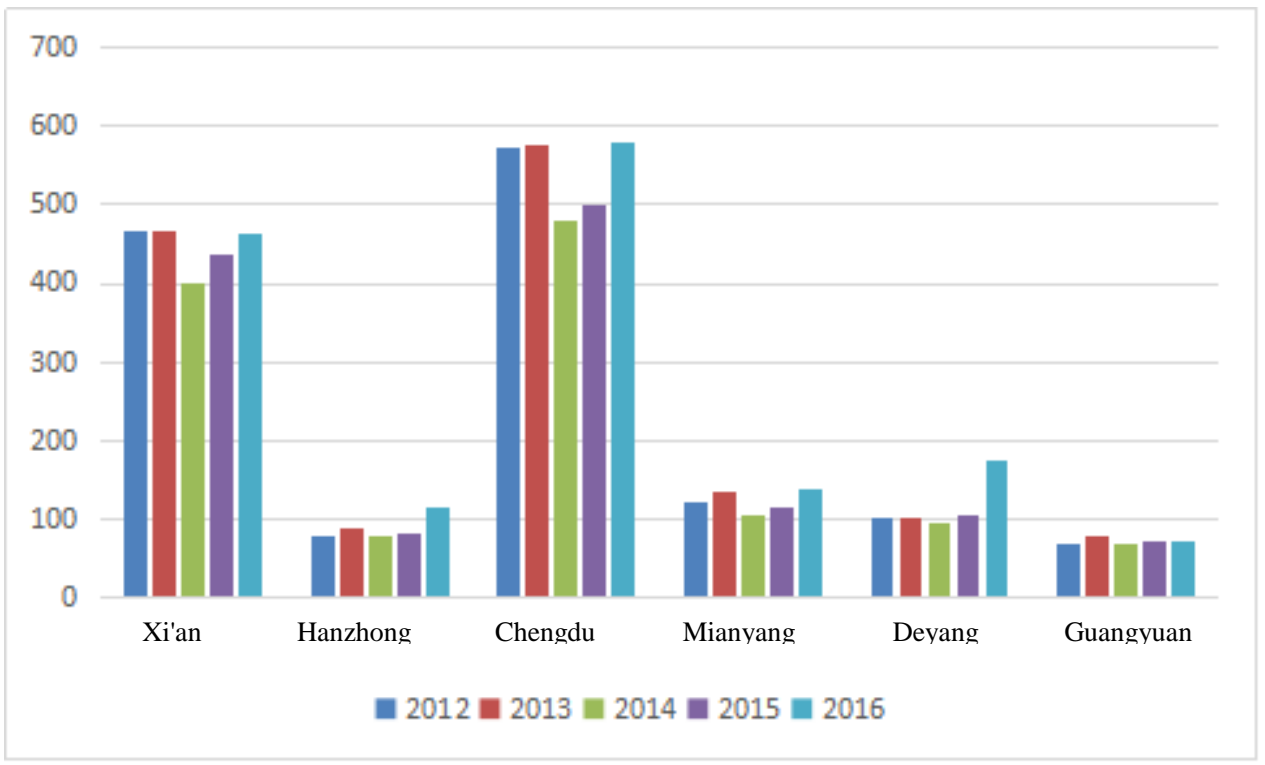

Fig. 6. Comparison of $R_{5}$ in 6 cities in the research area from 2012 to 2016.

\section{WAYS TO ENHANCE CITY'S CULTURAL COMPETITIVENESS}

According to the data of the research area from 2012 to 2016, the overall urban cultural competitiveness of the 6 cities has been rising significantly, especially Xi'an and Chengdu, showing that governments attach great importance to urban cultural competitiveness and make practical efforts. Obviously, the government of Guangyuan and Hanzhong has not done enough in this aspect. Therefore, the authors put forward the path to improve city's cultural competitiveness.

\section{A. Clearing strategy for cultural development}

The opening of Xi'an-Chengdu high-speed railway at the end of 2017 has had a significant sway on the economy of cities along the line. The cultural competitiveness of a city directly affects its attractiveness to the people. The promotion of strategic position of cultural competitiveness requires the improvement of cultural competitiveness of the city to a strategic level, which can drive the growth of the national economy and the upgrading of the industrial structure. Local governments should have a clear strategy for urban cultural development, formulate target strategies, adjust and optimize the structure of cultural industries from a strategic level, and identify industries and projects for priority development. [13] In consideration of the differences in cultural resources, human resources, technology and consumer demand among different cities in the research area, local governments may formulate targeted strategies to give priority to industrial and cultural development.

\section{B. Deepening cultural system reform}

The reform of cultural system is of great significance and an important part of China's all-round structural reform. In order to enhance the cultural competitiveness of cities in the research area, the comprehensive quality of cultural industry should be strengthened and the cultural system reform should be accelerated.

The focus of cultural system reform is to innovate the system, face the market, enhance vitality and transform the mechanism, remove the disadvantages that hinder the development of the cultural system and adopt innovative management and operation mechanism. The operation of cultural management calls for intensifying reform, improving the supervision of party committees and the government, and separating government administration from enterprise management. Enterprises should develop independently and realize their own value. Giving the promotion of the government and the role of the market, it is necessary to strengthen the comprehensive assessment 
of the social and economic benefits of cultural enterprises, and establish and improve the capital operation budget system, enabling them to achieve selfdevelopment, accumulation, financing and management. At present, Chengdu has a clear reform idea, the core of which is "one system, and two subsystems". The modern system of public cultural services has been basically improved. Xi'an should deepen the reform and construction of cultural management system and do a good job in all-round cultural development.

\section{Strengthening the system of public cultural services}

The public cultural service system affects citizens' consumption view and directly reflects the city's cultural competitiveness, which is an important part of the strategy for great development and prosperity of socialist culture. The imbalance of cultural and economic strength, urban and rural development and residents' consumption in research area lead to the imbalance of urban public cultural construction and development. As provincial capitals, Xi'an and Sichuan are stronger than the other four cities, but there also exists a gap between the duo. Therefore, the government should formulate strategies based on the actual situation, play a leading role, do a good job in macro-level regulation, strengthen the construction of cultural service network, improve public cultural infrastructure, and guarantee the cultural life of residents.

Public cultural facilities serve as the landmark of a city. The government should not only fulfill the service function in the field of culture, provide financial security and increase the construction of cultural facilities, but also improve its own team, encourage mutual supervision among various departments, do a good job in the evaluation and review, and ensure the implementation of cultural infrastructure construction.

\section{Enhancing the development of cultural tourism industry}

Due to the role of cultural tourism market in improving city's cultural competitiveness, the government departments set the construction of cultural tourism industry as the goal of urban development. As famous historical and cultural cities, Xi'an and Chengdu are relatively rich in cultural resources. Mianyang and Hanzhong are also famous tourist destinations in China with abundant cultural resources and solid foundation for cultural industry. Cities in the research area should ensure the development of cultural tourism resources and promote the healthy and orderly development of cultural tourism industry. The government departments should draw lessons from the developing cities and invest in the cultural tourism enterprises with good prospects, so as to drive the development. The government should also strengthen the management of employees, improve the quality of local residents, accelerate the construction of tourism infrastructure, regulate and control the tourism market, enhance publicity, and prompt the development of the tourism market.

\section{E. Pooling cultural and innovative talents}

Talent serves as the most important factor in urban cultural competition, especially innovative talent. Xi'an is the center of science and education in China, while Chengdu is home to many colleges and universities, which cultivate numerous high-quality talents every year. In order to gather cultural and innovative talents, cities in the research area should strengthen the training and education of local talents, implement talent training mode featuring multi-level, multi-channel and multicategory, accelerate the construction of training base, and provide a favorable environment for talent education. In addition, attention should also be paid to the introduction of talents, especially high-level cultural talents, so that they can contribute to the development of the city. Besides the cultivation and introduction of talents, the most important thing is to retain talents, which requires the establishment of new mechanism conducive to the growth of cultural talents, giving full play to their talents and helping them achieve achievements. [15] The last is to create talent highland, pool cultural elites and celebrities, and launch reasonable publicity to form celebrity effect.

\section{CONCLUSION}

Since urban culture involves political, economic, scientific and technological, natural, cultural and other factors, a system of urban cultural competitiveness should be created with the construction of cultural facilities, the general situation of cultural industry, cultural innovation, quality of life service, and cultural radiation power as index. This paper takes the cities along Xi'an-Chengdu high-speed railway as research area to study the urban cultural competitiveness, and concludes that the cultural competitiveness of each city is improving year by year, among which Chengdu and Xi'an perform better. The results show that the improvement of city's cultural competitiveness requires clarifying the strategy of cultural development, deepening reform of system, strengthening the construction of public cultural service system, enhancing the development of the cultural tourism industry and actively pooling cultural and innovation talents. It is hoped that the paper will contribute to the improvement of cultural competitiveness of cities along the railway. 


\section{References}

[1] Zhao Dexing, Chen Youhua, Li Huifen, Fu Qiyuan. Research on the Index System of Urban Cultural Competitiveness [J]. Social Sciences in Nanjing, 2006, (6): 26-31. (in Chinese)

[2] Wang Yicheng. The City Culture Modernization Indicator System and Appraisal [J]. Economic Geography. 2003, (2): 87 98. (in Chinese)

[3] Chen Long. Study on Evaluation and Analysis about Urban Cultural Competitiveness of Chongqing [D]. Chongqing University. 2017. (in Chinese)

[4] Gao Dongxin. Study on the Strategy and Path to Improve the Competitiveness of Urban Cultural Industry - Taking Xi'an City as an Example [J]. The Journal of Humanities, 2012, 1:108-113. (in Chinese)

[5] Zhang Jinhua. Research on Competitiveness Evaluation of Urban Culture - Comparative Analysis Based on 14 Cities Including Ji'nan [D]. Hebei University of Economics and Business. 2014. (in Chinese)

[6] Zhu Kai. Nanjing Ranks Fifth in Urban Cultural Competitiveness [N]. Nanjing Daily, 2017. (in Chinese)

[7] Xia Nan. Empirical Comparative Study of Urban Cultural Competitiveness under the Concept of Innovative Development [J]. Beijing Financial Review, 2018, 3:211-227. (in Chinese)

[8] Chang Sun Fu Rong. Strategies for Improving Tourist Satisfaction in Red Tourist Attractions [J]. Research On Development, 2018, 6: 154-160. (in Chinese)

[9] Cui Yan, Qiu Yue, Zheng Xin. Promotion Strategy of Folk Cultural Tourism from the Perspective of Experience Economy [J]. Research On Development, 2019, 2:123-128. (in Chinese)

[10] Wang Decheng. Analysis of the Development of Chengdu's Expansion Training Base [J]. Scenic Spots, 2019 (2): 273. (in Chinese)

[11] Wen Shouxun, Zhang Taisong. Evaluation System of City Competitiveness: Case of Main Cites in Middle and Western Regions of China [J]. Technology Economics, 2012, 4: 87-92. (in Chinese)

[12] Lei Zhaoyu. Shaping the Image of the Central City with the Strength of Urban Culture [J]. Journal of Chongqing Institute of Socialism, 2010, 6: 91-93. (in Chinese)

[13] Qin Ruiying. A Comparative Study of Guangzhou's Urban Cultural Competitiveness Based on Factor Analysis [J]. Research On Development, 2013, (4): 155-157. (in Chinese)

[14] Fang Cheng. On the Enlightenment of the Elephants' Dancing on Universities' Publishing Houses - Taking HD Publishing House for Example [J]. Studies of Finance and Accounting in Education, 2019, 1:62-67. (in Chinese)

[15] Tan Hong. Research on Cultural Competence of Chongqing [J]. Journal of Chongqing University of Arts and Sciences, 2009, 28 (5): 47-52. (in Chinese) 